\title{
Self-efficacy, Self-esteem and the Intention to Practice Safe Sex among Batswana Adolescents
}

\author{
${ }^{1}$ Rapelang Chilisa, ${ }^{2}$ Kagiso Tlhabano, ${ }^{3}$ Cedric Vista, ${ }^{4}$ Mpho Pheko, \\ ${ }^{5}$ Nonofo Losike, ${ }^{6}$ Sethunya Mosime, ${ }^{7}$ Kolentino Mpeta , ${ }^{8}$ Prof S. K. Balogun \\ 1,2,3,4,5,6,8 University of Botswana Department of Psychology \\ ${ }^{7}$ University of Botswana (Statistics
}

\begin{abstract}
Objective: This study, investigated whether high self-efficacy and high self-esteem could predict Batswana males and females intention to practice safe sex. Safe sex behaviors investigated included, consistent use of condoms, abstinence from sex and sticking to one partner.

Method: A self reported anonymous questionnaire was used to collect data from 286 young people aged between 13 and $19(M=15.02, S D=1.02)$ of which 283 were native citizens of Botswana.

Results: Data was analyzed using the Statistical Package of Social Sciences (SPSS). Prior to using multiple regression analysis to predict safe sex practices, Pearson's correlations were conducted on the two independent variables (self-efficacy, self-esteem) and the outcome variable (safe sex behaviors). The findings suggested that intention to limit partners, intention to abstain and intention to use condoms correlated positively with high selfefficacy. High self-esteem exhibited low correlations with the afore-mentioned sexual behaviors. Multiple regression analysis also showed that self-efficacy had a stronger predictive power on the safe sex behaviors under study in comparison to high self-esteem.

Conclusion: There has been contradicting evidence on some of the literature on whether high self-esteem is better predictor of safe sex practices. In the current study there were no strong positive correlations exhibited on high self-esteem and safe sex behaviors, rather, high self-efficacy was a better predictor of safe sex practices. The country of Botswana has been battling the fight against HIV/Aids for decades and with the current focus being on behavior change, studies like the current will better inform intervention measures used in curbing the spread of HIVIAIDS.
\end{abstract}

Keywords: HIV/AIDS; safe sex; Self-efficacy; self-esteem;

\section{Background of Botswana}

Despite the existence of many notable HIV/AIDS programs in Botswana, HIV spread and prevalence is still a concern in the country with prevalence rates estimated at 17. 6 ((Botswana AIDS Impact Survey (BAIS) III, 2008). This number include 18000 children aged 10 - 19. A good number of adolescents are not diagnosed and as such their HIV status remains unknown to them (Botswana AIDS Impact Survey III, 2008). The survey reports that there is a tendency among adolescents to have more than one sexual partner. Further, the same AIDS Impact Survey showed that only 78\% of people aged between 15 and 24 consistently use condoms.

Clearly, the HIV epidemic is already prevalent among adolescents and young people in Botswana. While the prevalence dropped between 2004 and 2008 among this population, research revealed that by the time adolescents are 17 years, half of the boys and girls in Botswana would have had their first sexual encounter (Botswana AIDS Impact Survey III, 2008). The same study indicates that compared to boys, girls remain twice as likely to be infected with the virus. Exacerbating this problem is the existence of intergenerational sex among young people, of which the BIAS III estimates that 7\% of adolescents aged 15-19 years who have had sexual intercourse in the 12 months preceding the survey did so with a partner who was 10 or more years older.

With the help of the international community and solicitation of funds, the government of Botswana embarked on the challenging journey of containing the epidemic by implementing ways of reducing the mortality rate of those infected as well as to curb new infection rates. In this study we report on the extent to which self-efficacy and self-esteem influence safe sex practices among a sample of Batswana adolescents. In the current study safe sex practices referred to intention to limit partners, intention to abstain from sex, and intention to use condoms.

\section{Adolescents and Safe Sex}

Young adulthood is a time typified by experimentation, which may include taking part in risky behaviors such as sexual activities (Moore \& Parsons, 2000). In particular, adolescents' relationships are also characterized by serial monogamy (Seidman \& Rieder, 1994), this fondness to engage in multiple brief 
relationships quickly adds to the number of persons to whom the adolescent is directly exposed (Morrison, Oxford, Gillmore, Richey \& Balassone, 2000). In light of the HIV/AIDS pandemic that hit Botswana among other nations, it is imperative that risky sexual behaviors among the youth be addressed to avert the spread of HIV/AIDS. For example, with regards multiple sexual partnership in Botswana, the BAIS III for 2008 showed that $11.2 \%$ of those whose age ranged from 15-49 had multiple partners, this included adolescents.

While the most effectual method of preventing sexually transmitted infections (STIs) in the adolescent population, is among others unfailing and accurate condom use, adolescents' use of condoms is usually not only inconsistent but also unsatisfactory (Kihara, 2000), this as a result, exposes adolescents to the high risk of getting sexually transmitted infections including HIV (American Association for World Health, 1998). In Botswana for example, the World Bank (2010), studies showed that engaging in unprotected sex was among the factors that escalated the epidemic, therefore calling for the need to investigate on predictors of safe sex behaviors such as consistent use of condoms, particularly in the nations hardest hit by HIV/AIDS, such as Botswana.

\section{Self-Efficacy}

Efficacy has been defined as the individual's belief in their capability and capacity to carry out goaldirected behaviors within an activity context. It is how confident one feels about tackling certain tasks, challenges, and contexts (Fredrick-Recascino, 2004; Goetz, Cronjaeger, Frenzel, Ludtke \& Hall, 2010; Hughes, Galbraith \& White, 2010). Perceived self-efficacy, as put forth by Bandura, has been suggested to be a strong predictor of carrying out a recommended deed (Bandura et al, 1977). In general, it is reported that persons who have confidence in their ability tend to view difficult tasks as meaningful challenges, even while others may deem similar tasks as discouraging. A lack of self-efficacy therefore may result in the individual having low aspirations, not trying harder and even giving up easily (Tsai, Chuang, Liang \& Tsai, 2011).

In the context of the current paper, self-efficacy -the perception that one can engage in protective behavior has been highlighted as a key factor in predicting health-promoting behaviors (Bandura, 1986). One of such behaviors is condom self-efficacy, which is the individual's belief in their ability to use condoms effectively. Condom self-efficacy has been found to be a substantial predictor of engaging in safe sex behaviors (Basen-Engquist \& Parcel, 1992; Brown, Danovsky, Lourie, DiClemente \& Ponto, 1997; Jemmott \& Jones, 1993). In addition, Basen-Engquist and Parcel (1992) discovered that after controlling for attitudes and perceptions of peer norms towards safer sex, condom self-efficacy predicted condom use. Further, in another study that assessed a sample of $10^{\text {th }}$ graders, students who believed they could use condoms effectively were more likely to report consistent use of condoms in comparison to their less confident counterparts (Kasen, Vaughan, \& Walter, 1992).

In a separate study considering how well optimism about the future and self-esteem predict condom use self-efficacy, Bryan, Aiken, and West (2004) depicted self-efficacy as a multi-dimensional construct that comprise skills at condom use, social aspects of negotiating condom use with one's sexual partner as well as the ability to use condoms while under the influence of alcohol and drugs. They considered communication to be among the factors of the self-efficacy model. Communication factors therefore speak to the capability of one to be assertive in their discussion with their sexual partner about the intent to use a condom and the capability to negotiate condom use even when faced with dissatisfaction or objection from the partner (Bryan, Aiken, \& West, 2004). The above observation supported the relationship of self-efficacy to condom-use intention noted before in other populations (Dilorio et al., 2000; Meekers \& Klein, 2002; Taffa et al., 2002).

It thus seems apparent that one's belief in their ability to use condoms effectively may be an important factor to take into account in designing HIV prevention measures for adolescents (Lescano, Brown, Miller \& Puster, 2007). Even more so, when considering the fact that self-efficacy as a predictor of safe sex behavior continues to be reported in more recent studies (Buhi \& Goodson, 2007; Hendrickx, Philips \& Avonts, 2008; Heeren, Jemmott III, Mandeya \& Tyler, 2007). Furthermore, Hendrickx, et al. (2008) also identified the selfefficacy variable as an important associate of safe sex intentions and behavior in their sample of Belgian adolescents in both native and ethnic minorities. In their case, self-efficacy entailed the ability to suggest that a condom be used in a sexual relationship, the capability to employ a condom properly, and the confidence to use a condom. Also noteworthy is the findings made by Heeren, Jemmott III, Mandeya \& Tyler (2007)'s study of the predictive value of the theory of planned behavior in a sample of university students in South Africa and the United States. Heeren et al.'s (2007) study identified self-efficacy among other variables as an important predictor of both condom use and intention to use condoms. Further, it has been shown that young people with greater motivational readiness and self-efficacy for safer sex were more likely to utilize condoms (Outlaw, Naar-King, Janisse \& Parsons, 2010). This in some way harmonized with earlier reports that self-efficacy mediated the relationship between motivational readiness to change and condom use (Naar-King et al. 2006).

From the literature, it was gathered that not much has been documented on self-efficacy's role on other safe sex practices besides condom use. In joining the quest to identify effective predictors of safe sex, the 
current paper goes beyond condom efficacy to include self-efficacy's role in the intention to limit sexual partners and intention to abstain from sex.

\section{Self-esteem}

Self-esteem, the individuals' opinion of their self-worth or their ability to feel positive about themselves has also been identified as one of the factors that have the potential to influence health behaviors (De Bruijin, Kremers, van Michelen \& Brug, 2005). Researchers have revealed a significant association between health behaviors and adolescents' self-esteem (Neumark-Sztainer, Paxton, Hannan, Haines \& Story, 2006). More recently, Geçkil and Dündar (2011) noted an important association between self-esteem and health risk behaviors of adolescents in their study. Specifically, they found that adolescents who scored low on self-esteem had higher scores for health risk behaviors.

A key argument has been that low self-esteem places the individual at a high risk for taking part in risky behaviors such as risky sexual activities, including having unprotected sex and not limiting sexual partners (Lejuez, Simmons, Aklin, Daughters \& Dvir, 2004; Preston et al., 2004; Wild, Flisher, Bhana, \& Lombard, 2004). Others such as Lejuez et al. (2004) documented that low self-esteem was linked to unsafe sexual behavior among adult residents of a drug treatment programme. Another study utilizing a large crosssectional sample of South African adolescents observed that low self-esteem was linked to a number of risky behaviors including unprotected sex (Wild et al., 2004). It however remains unclear whether high self-esteem is a good predictor of safe sex behaviors especially when some of the literature reports on an inverse relationship between high self-esteem and risky sexual behavior (Hollard et al., 1996).

The purpose of the current study was to add to existing research on self-efficacy and self-esteem's role in safe sex behavior by investigating the extent to which self-efficacy and self-esteem influence safe sex practices among a sample of Batswana adolescents. In the current study safe sex practices referred to intention to limit partners, intention to abstain from sex, and intention to use condoms. In line with the above discussions, the hypotheses are as follows;

1. Adolescents' intention to practice safe sex would be positively correlated with high scores on selfefficacy.

2. Adolescent's intention to practice safe sex would be positively correlated with their high level of self-esteem.

\section{Method}

Participants

A sample survey of 286 young people aged between 13 and 19 comprising 98 males and 183 females was used. Of the total sample, 283 were citizens of Botswana, three were from a different nationality and five did not indicate their gender. All participants were junior secondary school students, aged between 13 and 19 years. Multistage cluster sampling was used to select one region out of the five Botswana school inspectorial regions. Within the selected region, eight schools (3 urban, 3 semi-urban and 2 rural schools) were randomly selected to participate in the study. The resultant sample consisted of students randomly selected from each of the eight schools.

\section{Instruments}

Self-efficacy on the three sexual behaviors; intention to abstain from sex, intention to use condom and intention to limit partners was measured through examining specific items from the broader scales used in assessing adolescents sexual attitudes and behaviors. Table 1 shows the descriptive statistics and the reliability index using Cronbach alpha for the scales measuring the intention to practice abstinence, intention to limit partners, intention to use condoms, abstinence self-efficacy, limiting partners self-efficacy, condom use selfefficacy and self-esteem. All the scales except the abstinence self-efficacy scale are highly reliable with alpha coefficients of between 0.752 and 0.832 .

To measure self-esteem, the study utilized the Rosenberg Self-Esteem Likert scale, comprising in total ten item statements which enquired on whether the individual strongly agreed, agreed, disagreed or strongly disagreed with the statements that enquired on their evaluations of themselves. Worth noting is that, with the current study another column on "neither agree nor disagree" was added to the responses. In scoring the items, the positive statements were given points as follows; Strongly Agree $(\mathrm{SA})=3$, Agree $(A)=2$, Disagree $(\mathrm{D})=1$ and Strongly Disagree $(\mathrm{SD})=0$ while the negative statements were reversed scored as follows; $\mathrm{SA}=0, \mathrm{~A}=1$, $\mathrm{D}=2$ and $\mathrm{SD}=3$ and finally summing the numbers to get the score for the overall self-esteem. The scores were interpreted to mean that the higher the sum number, the higher the individual's self-esteem, refer to (table 2) for the reliability alpha scores of the scale. The self esteem mean was 16.1 with while the highest score was 24 and the lowest score was 4 . The participants generally scored low on self esteem. 
Table 1: The scales, descriptive statistics and the reliability index

Variable

No $\mathrm{Me}$ SD $\alpha$

of an

ite

$\mathrm{ms}$

\section{Intention to abstain}

I plan to abstain in the next 3 months,

I will try my level best to abstain in the next 3 months

Intention to limit partners

I plan to stick to one partner if I am to have a partner in the next 3 months,

How likely is it that you would stick to one partner if you were to have a partner in

the next 3 months,

I will try my level best to stick to one partner if I have a partner in the next 3 months

\section{Intention to use condoms}

I will try my level best to use condoms if I have sex in the next 3 months,

I plan to always use a condom if I have sex in the next three months

\section{Abstinence self efficacy}

I can abstain from sex even if I have had sex in the past,

I am sure I will abstain in the next 3 months

\section{Limiting partners self efficacy}

I am sure I will stick to one partner in the next 3 months,

How sure are you that you could stick to one partner in the next 3 months

\section{Condom use self efficacy}

I can talk to the person with whom I have sex about using condoms, I can get the person with whom I have sex to use a condom, even if he/she doesn't

want me to use a condom,

I can say to the person with whom I have sex that we should use a condom, Before we

are ready to have sex,

I can talk to the person with whom I have sex about using a condom, If my partner and I

do not have a condom,

I can say no to sex, I am sure that I can always use a condom if I have sex,

How easy or hard would it be to use condoms when you have sex?

\section{Self esteem score}

$\begin{array}{llll}2 & 3.9 & 1.21 & 0.83 \\ 1 & 7 & 0\end{array}$

$\begin{array}{llll}3 & 3.8 & 1.10 & 0.83\end{array}$

$6 \quad 0 \quad 2$

2

$\begin{array}{lll}4.1 & 0.97 & 0.77\end{array}$

$\begin{array}{llll}2 & 3.6 & 1.05 & 0.46 \\ & 5 & 6 & 4 \\ & & & \\ 2 & 3.8 & 1.35 & 0.78 \\ & 2 & 7 & 2 \\ & & & \\ 7 & 3.86 & 0.76 & 0.80 \\ & & 7 & 9\end{array}$

\section{Procedure}

Ethical approval was obtained from the Institute of Review Board (IRB) Ministry of Health, Republic of Botswana. In addition, relevant heads of schools gave the researchers authority to use students as participants. Written consent was also obtained from the adolescent's parents as well as from the adolescents. 


\section{Adolescents Sexual Behaviors}

\section{Results}

The survey revealed that a total of 36 respondents (13\%) had indulged in sexual intercourse. The mean age at sexual debut for females was $14.55(\mathrm{SD}=1.214)$ compared to $10.85(\mathrm{SD}=3.911)$ for males.

Boys reported seeing more sexual partners compared to girls. A one-way ANOVA comparison of the mean age at sexual debut between boys and girls showed a statistically significant difference $(p=0.005)$. Girls experienced first sexual intercourse with partners older than them. The average age for girls' sexual partners was 16.25 years while that for boys' sexual partners was 13.8 years. The minimum age of the girls, sexual partner was 14 years compared with 7 for boys. The maximum age was 20 for girls' sexual partners compared with 18 for boys. The results also show that only about $30 \%$ of the adolescents used condoms all the time thus they are at risks of contracting HIV. See Table 2

Table 2: Socio demographic variable of respondents

\begin{tabular}{|c|c|c|c|}
\hline Variables & boys $(n=98)$ & girls $(n=187)$ & all $(n=286)$ \\
\hline Mean age of participant & \multirow{2}{*}{\multicolumn{2}{|c|}{$15.14(\mathrm{SD}=1.121)$}} & $14.97(\mathrm{SD}=0.960)$ \\
\hline $15.02(\mathrm{SD}=1.017)$ & & & \\
\hline Ever had sexual intercourse & $23(24.0 \%)$ & & $7.2 \%)$ \\
\hline $36(13.0 \%)$ & & & \\
\hline Mean age at first sexual intercourse & \multirow[t]{2}{*}{$10.85(\mathrm{SD}=3.911)$} & \multirow[t]{2}{*}{$14.55(\mathrm{SD}=1.214)$} & 14) \\
\hline $12.27(\mathrm{SD}=3.582)$ & & & \\
\hline Maximum number of partners & 15 & 4 & \\
\hline Mean age of sexual partner & \multicolumn{2}{|c|}{$13.83(\mathrm{SD}=3.457)$} & $16.2(\mathrm{SD}=2.121)$ \\
\hline Sexual partner other than partners had & 2 & 2 & 2 \\
\hline Did not use condoms & \multirow[t]{2}{*}{$3(23.1 \%)$} & \multirow[t]{2}{*}{$1(20.0 \%)$} & \\
\hline $4(22.2 \%)$ & & & \\
\hline Used condoms sometimes & $2(15.4 \%)$ & - & $2(11.1 \%)$ \\
\hline Used condom often & \multirow{2}{*}{\multicolumn{2}{|c|}{$2(15.4 \%)$}} & \multirow[t]{2}{*}{-} \\
\hline $2(11.1 \%)$ & & & \\
\hline Used condoms almost every time & $2(15.4 \%)$ & $1(20.0 \%)$ & $3(16.7 \%)$ \\
\hline Used condom every time & $4(30.8 \%)$ & $3(60.0 \%)$ & $7(38.9 \%)$ \\
\hline
\end{tabular}

One of our main research questions was to determine the relationship between self-efficacy and safe sex behaviours as well as self-esteem and safe sex behaviours. A Pearson correlation revealed a positive strong relationship between self-efficacy and safe sex behaviors. As shown in Table 3, the correlation coefficient between intention to limit partners and limiting partners self efficacy was $0.679(p<0.01)$, the correlation coefficient between intention to abstain from sex and abstinence self efficacy was 0.708 ( $p<0.01)$ and the correlation coefficient between intention to use condoms and condom use self efficacy was 0.7 ( $p<0.01)$.

Table 3: Correlations on safe sex intentions and self-efficacy

\begin{tabular}{|c|c|c|c|}
\hline \multirow[t]{2}{*}{ Variable } & \multirow{2}{*}{$\begin{array}{r}\text { Limiting partners } \\
\text { Self efficacy }\end{array}$} & \multicolumn{2}{|c|}{ Abstinence $\quad$ Condom use } \\
\hline & & self efficacy & self efficacy \\
\hline Intention to limit partners & $0.679 * *$ & & \\
\hline Intention to abstain from sex & & $0.708 * *$ & \\
\hline Intention to use condoms & & & $* *$ \\
\hline
\end{tabular}

\section{$* * \mathrm{p}<0.01$}

On self esteem and safe sex behavours the results showed a weak relationship though statistically significant. The Pearson correlation coefficient between self esteem score and intention to limit partners was 0.316 ( $\mathrm{p}<0.01$ ), the correlation coefficient between intention to abstain from sex and the self esteem score was $0.323(\mathrm{p}<0.01)$ while the correlation coefficient between intention to use condoms and self esteem score was $0.336(\mathrm{p}<0.01)$.

Table 4

Correlations on safe sex intention variables and self-esteem

\begin{tabular}{ll}
\hline Variable & Self Esteem Score \\
\hline Intention to limit partners & $0.316^{* *}$ \\
Intention to abstain from sex & $0.323^{* *}$ \\
Intention to use condoms & $0.336^{* *}$ \\
\hline
\end{tabular}


$* * \mathrm{p}<0.01$

In the second research question we sought to determine the predictive power of self efficacy and self esteem on safe sex behaviours. A multiple regression analysis was performed with safe sex behaviours as the dependent variables and self-efficacy and self-esteem as independent variables.

The Multiple regression analysis of intention to limit partners on self esteem score and limiting partners selfefficacy revealed that both the self-esteem score and limiting partners self-efficacy predicted intention to limit partners. The model accounted for almost $49 \%$ of the variance with self efficacy accounting for most of the variance. Both regression coefficients were statistically significant $(\mathrm{p}<0.01)$, which shows that they had an independent effect on intention. See Table 5.

Table 5: Multiple regression analysis of Intention to limit partners on self-esteem score and limiting partners self-efficacy

$\begin{array}{lccc}\text { Predictor } & \mathrm{B} & \mathrm{SE}_{\mathrm{B}} & \mathrm{R}^{2} \\ & & & 0.489 * * \\ \text { Self-esteem } & 0.040 * * & 0.010 & \\ \text { Self-efficacy } & 0.511 * * & 0.037 & \end{array}$

$* * \mathrm{p}<0.01$

The multiple regression analysis of Abstinence intention on self-esteem score and abstinence self-efficacy revealed that both the self esteem score and abstinence self efficacy predicted abstinence intention. Both regression coefficients were statistically significant $(\mathrm{p}<0.01)$, which shows that they had an independent effect on intention. The model accounted for $54 \%$ of the variance with self efficacy accounting for most of the variance. See Table 6.

Table 6: Multiple regression analysis of Abstinence intention on self-esteem score and abstinence self-efficacy

\begin{tabular}{lccc}
\hline Predictor & $\mathrm{B}$ & $\mathrm{SE}_{\mathrm{B}}$ & $\mathrm{R}$ \\
& & & 0.54 \\
Self esteem score & $0.052^{* *}$ & 0.011 & \\
Self-efficacy & $0.755^{* *}$ & 0.049 \\
\hline
\end{tabular}

$* * \mathrm{p}<0.01$

Multiple regression analysis of Condom use intention on self esteem score and condom use selfefficacy showed that both the self-esteem score and condom use self efficacy predicted abstinence intention. Both regression coefficients were statistically significant $(\mathrm{p}<0.01)$, which shows that they had an independent effect on intention. The model accounted for almost $50 \%$ of the variance with self efficacy accounting for most of the variance. See Table 7

Table 7: Multiple regression analysis of Condom use intention on self esteem score and condom use selfefficacy

\begin{tabular}{lccc}
\hline Predictor & $\mathrm{B}$ & $\mathrm{SE}_{\mathrm{B}}$ & $\mathrm{R}^{2}$ \\
& & & $0.498^{* *}$ \\
Self esteem score & $0.020^{* *}$ & 0.009 & \\
Self-efficacy & $0.844^{* *}$ & 0.059 & \\
\hline
\end{tabular}

$* * \mathrm{p}<0.01$

\section{Discussion}

The purpose of the current study was to investigate the extent to which self-efficacy and self-esteem influence safe sex practices among a sample of Batswana adolescents. In the current study safe sex practices referred to intention to limit partners, intention to abstain from sex, and intention to use condoms. We thus hypothesized that high self-efficacy would predict adolescent's intention to practice safe sex. Secondly, we hypothesized that high self-esteem would also predict the intention to practice safe sex. The findings from the study showed that self-efficacy was a better predictor of intention to practice safe sex than high self esteem. Consistent with some of the literature that reported a poor relationship between high self-esteem and safe sex behavior (Seal, Minichiello \& Seal, Minichiello \& Omodei, 1997), the current study revealed a low correlation compared to self-efficacy and safe sex behaviors, thus making self-efficacy a better predictor of safe sex behavior than self esteem. 
Other studies identified the self-efficacy variable as an important associate of safe sex intentions and behavior (Buhi \& Goodson, 2007; Hendrickx et al., 2008; Heeren et al, 2007). In addition to the majority of previous research, which noted condom efficacy as a good predictor of intention to practice safe sex, the current study revealed that efficacy on limiting partners and abstinence are also good predictors of practicing safe sex. The current study thus enhances knowledge on predictors of safe sex behavior, by showing that the individual's confidence in their ability to limit sexual partners, to abstain from sex, and to use condoms heightens their chances of practicing safe sex.

Concerning the link between self-esteem and safe sex practices, there was no strong correlation between high self esteem and the intention to practice safe sex among adolescents. Multiple regression of the two independent variables also showed that self-efficacy had more predictive power of the outcome variables on safe sex behaviors compared to high self-esteem. This is consistent with several of the findings documented earlier which found no strong relationship between self-esteem and safe sex behavior (Abel, Adams \& Stevenson, 1994; Neumark-Sztainer, Story, French, and Resnick, 1997; West \& Sweeting, 1997). While some studies have linked low self-esteem to risky sexual behavior such as having multiple sexual partners and engaging in unprotected sex (Lejuez, Simmons, Aklin, Daughters \& Dvir, 2004; Preston et al., 2004; Bhana, \& Lombard, 2004), others have linked high self-esteem to risky sexual behaviors (Seal, Minichiello \& Seal, Minichiello \& Omodei, 1997). The inconsistency in the findings necessitates continued research on selfesteem's predictive value on safe sex practices. The current study revealed that self-efficacy was a better predictor of safe sex practices as opposed to high self-esteem.

The findings on age at first sexual intercourse are also consistent with other studies whereby the survey revealed that a total of 36 respondents $(13 \%)$ had indulged in sexual intercourse. The 2005 Botswana Global School-Based Health Survey of 2,197 students aged between 13 and 15 reported that $17.4 \%$ had experienced sexual intercourse. The Botswana AIDS Impact Survey II reported that out of the 731,174 respondents between the ages of 10-64 years old, the majority (55\%) had their first sexual encounters when they were between the ages of 15 and 19 years. About half of the Batswana youth are active before their $18^{\text {th }}$ birthday and thus exposed to the risks of HIV infection. Among reasons given for why more boys were likely to have sexual intercourse compared to girls are that boys may perceive sex as a symbol of masculinity and power domination over girls (Brown, Sorrell and Raffaelli 2005). Boys are also reported to demonstrate their power by having sex with many girls (Mufune 2003).

\section{Limitations}

Data in the current study was obtained through the use of self-report instruments and this could have created the problem of common method bias (Spector, 1994). The study utilized participants schooling in the urban parts of the country of Botswana and therefore may not generalize to the entire Batswana adolescents, especially those schooling in remote areas.

\section{Recommendations for Future Research}

While the current study supported the hypothesized relationship on self-efficacy and safe sex behaviors, research findings on the association between self-esteem and safe sex practices are contradictory. For instance, some studies have documented a link between higher self-esteem and unsafe sex, i.e. (Seal, Minichiello \& Omodei, 1997), while, other studies have found no relationships between self-esteem and risky sexual behavior (Abel, Adams \& Stevenson, 1994; Neumark-Sztainer, Story, French, and Resnick, 1997; West \& Sweeting, 1997).

To fully explore this seemingly contradictory relationship between self-esteem and safe sex practices, it is recommended that in future, a variety of instruments assessing self-esteem could be utilized. This may entail using both global self-esteem measures and specific sexual self-esteem measures. Moreover, given this complex and contradictory relationship between safe sex and self-esteem, future research may also investigate self-esteem as either a moderator or a mediator of the proposed relationships.

\section{Acknowledgements}

This research is part of a larger study funded by the National Institute for Health in the USA grant 124HD056693-05 to study adolescents' risky behaviours in Botswana. It is a partnership between The University of Botswana and The University Pennsylvania with the PI as Bagele Chilisa from Botswana and COPI as John Jemmott from The University of Pennyslavania. 


\section{References}

[1]. Abel, E., \& Adam, E. (1994). Self-esteem, problem solving, and sexual risk behaviour among women with and without Chlamydia. Clinical Nursing Research 3(4) p353. 18p

[2]. Bandura, A. (1986). Social foundations of thought and action: A social cognitive theory. Englewood Cliffs, NJ: Prentice hall.

[3]. Bandura, A. (1977). Self-efficacy: toward a unifying theory of behavioural change. Psychological Review 84(2) 191-216. Doi:10.1037/0033-295x.84.2.191

[4]. Basen-Engquist, K. \& Parcel, G.S (1992). Attitudes, norms, and self-efficacy: A model of adolescent's HIV-related sexual risk behaviour. Health Education Quarterly, 19, 263-277

[5]. Bryan, A., Aiken, L. S., \& West, S. G. (2004). HIV/STD risk among incarcerated adolescents: Optimism about the future and selfesteem as predictors of condom use self-efficacy. Journal of Applied Social Psychology, 34(5), 912-936. doi:10.1111/j.15591816.2004.tb02577.x

[6]. Brown, J., Sorrel, J. \& Raffaeli, M. (2005). An exploratory study of construction of masculinity, sexuality and HIV/AIDS in Namibia, Southern Africa. Culture, Health, and Sexuality, 7(6), 585-598. DOI:0.1080/13691050500250198

[7]. Buhi, E.R. \& Goodson, P. (2007). Predictors of adolescent sexual behaviour and intention. Journal of Adolescent Behavior, 40(2007) 4-2. Doi: 10.1016/j.jadohealth.2006.09.027

[8]. Çetinkalp, Z., \& Turksoy, A. (2011). Goal orientation and self-efficacy as predictors of male adolescent soccer players' motivation to participate. Social Behavior \&Personality: An International Journal, 39(7), 925-934. doi:10.2224/sbp.2011.39.7.925

[9]. Czuchry, M. M., Timpson, S. S., Williams, M. L., Bowen, A. M., \& Ratliff, E. A. (2009). Improving condom self-efficacy and use among individuals living with HIV: The positive choices mapping intervention. Journal of Substance Use, 14(3/4), 230-239. doi:10.1080/14659890902874212.

[10]. De Bruijin, G.J., Kremers, S.P.J., Van Mechelen, W., \& Brug, J. (2005). Is personality related to fruit and vegetable intake and physical activity in adolescents? Health Education Research, 20, 635-644

[11]. DiIorio, C., Dudley, W. N., Lehr, S., \& Soet, J. E. (2000). Correlates of safer sex communication among college students. Journal of Advanced Nursing, 32(3), 658-665. doi:10.1046/j.1365-2648.2000.01525.x.

[12]. Geckil, E. \& Dundar, O. (2011). Turkish adolescent health risk behaviours and self-esteem. Social Behaviour and Personality: An International Journal. 39(2) 219-227

[13]. Goodson, R. C., \& Buhi, E.R. (2007). Texas abstinence educator's self-efficacy to motivate youth sexual abstinence. American Journal of Sexuality Education, 2(3) p59. 20p. Doi:10.1300/J455V02n03 05.

[14]. Goetz, T., Cronjaeger, H., Frenzel, A.C, Ludtke, O. \& Hall, N.C. (2010). Academic self-concept and emotion reflections: Domain specificity \& age effects. Contemporary Education Psychology 35(1) 44-58

[15]. Heeren, G., Jemmott III, J. B., Mandeya, A., \& Tyler, J. C. (2007). Theory-based predictors of condom use among university students in the United States and South Africa. AIDS Education \& Prevention, 19(1), 1-12.

[16]. Hendrickx, K., Philips, H., \& Avonts, D. (2008). Correlates of safe sex behaviour among low-educated adolescents of different ethnic origin in Antwerp, Belgium. The European Journal of Contraception and Reproductive Health Care, 13(2), 164-172. doi:10.1080/13625180802011385

[17]. HIV \& AIDS in Botswana (2012). Retrieved from http://www.avert.org/aids-botswana.htm on June 14, 2012.

[18]. Hollar, D.S., \& Sniezek, W.E. (1996). The Influences of knowledge of HIV/AIDS and self-esteem on the sexual practices of college students. Social Behaviour and Personality, 24, 75-86

[19]. Hughees, A., Galbraith, D. \& White, D. (2011). Perceived competence: A common core for self-efficacy and self-concept? Journal of Personality Assessment, 93(3), 278-289. Doi:10.1080/00223891.2011.559390

[20]. Kasen, S. Vaughan, R.D. \& Walter, H.J (1992). Self-efficacy for AIDS preventive behaviours among tenth-grade students. Health Education Quarterly, 19, 187-202

[21]. Klassen, R. M., \& Lynch, S. L. (2007). Self-efficacy from the perspective of adolescents with LD and their specialist teachers. Journal of Learning Disabilities, 40(6-), 494-507.

[22]. Klein, H., Elifson, K. W., \& Sterk, C. E. (2010). Self-esteem and HIV risk practices among young adult ecstasy users. Journal of Psychoactive Drugs, 42(4), 447-456. doi:10.1080/02791072.2010.10400707

[23]. Kaneko, N. (2007). Association between condom use and perceived barriers to and self-efficacy of safe sex among young women in Japan. Nursing and Health Sciences, 9,284-289.

[24]. Kowal, A. K., \& Blinn-Pike, L. (2004). Sibling Influences on adolescents' attitudes toward safe sex practices. Family Relations: An Interdisciplinary Journal of Applied Family Studies, 53(4), 377-384. doi:10.1111/j.0197-6664.2004.00044.x

[25]. Lejuez, C. W., Simmons, B. L., Aklin, W.M., \& Daughters, S. B. (2004). Risk-taking propensity and risky sexual behaviour of individuals in residential substance use of individuals in residential substance use treatment. Addictive Behaviors $29(8) 1643-1647$. 5p. Dol: 10.1016/jaddbeh.2004.02.035.

[26]. Lescano, C. M., Celia, L. K., Miller, P. M., \& Puster, K. L. (2007). Unsafe sex: Do feelings matter? Journal of Prevention \& Intervention in the Community, 33(1/2), 51-62. doi:10.1300/J005v33n01-05

[27]. Maccio, E. M., \& Schuler, J. T. (2012). Substance use, self-esteem, and self-efficacy among homeless and runaway youth in New Orleans. Child \& Adolescent Social Work Journal, 29(2), 123-136. doi:10.1007/s10560-011-0249-6

[28]. Magnani, R. J., Seiber, Eric E.; Gutierrez, Emily Zielinski; Vereau, Dorina (2201). Correlates of sexualactivity and condom use among secondary school students in urban Peru. Studies in Family Planning, 32(1) p53. 14p

[29]. Mufune, P. (2003) Changing patterns of sexuality in northern Namibia: Implications for the transmission of HIV/ AIDS. Culture, Health and Sexuality, 5, 425-438.

[30]. Morrison, D. M., Oxford, M. L., Gillmore, M., Richey, C. A., \& Balassone, M. (2000). Negotiating Condom Use: Partner Type and Gender Effects. Journal of HIV/AIDS Prevention \& Education for Adolescents \& Children, 3(4), 29

[31]. Moore S, Parsons JT (2000). A research agenda for adolescent risk-taking: Where do we go from here Journal of Adolescence. 23(4):371-376.

[32]. Naar-king, S., Wright, K. , Parsons, J., Frey, M., Templin, T., Lamp, P., \& Murphy, D. (2006). Healthy choices: Motivational enhancement therapy for health risk behaviors in HIV+ youth. AIDS Education and Prevention, 18, 1-11. Doi: 10/1521/aeap.2006.1.1

[33]. Neumark-sztainer, D., Paxton, S.J., Hanna, P. J., Hanes, J. \& Story, M. (2006). Does body satisfaction matter? Five year longitudinal association between body satisfaction and health behaviors in adolescent females and males. Journal of Adolescent Health 39(2) 244251

[34]. Oattes, M., \& Offman, A. (2007). Global self-esteem and sexual self-esteem as predictors of sexual communication in intimate relationships. Canadian Journal of Human Sexuality, 16(3/4), 89-100.

[35]. Outlaw, A., Naar-King, S., Janisse, H., \& Parsons, J. T. (2010). Predictors of condom use in a multisite study of high-risk youth living with HIV. AIDS education and prevention, 22(1), 1-14. doi:10.1521/aeap.2010.22.1.1 
[36]. Rosenthal, D., Moore, S., \& Flynn, I. (1991). Adolescent self-efficacy, Self-esteem and sexual risk-taking. Journal of Community \& Applied Social Psychology, 1(2), 77-88.

[37]. Rostosky, S., Dekhtyar, O., Cupp, P. K., \& Anderman, E. M. (2008). Sexual self-concept and sexual self-efficacy in adolescents: A possible clue to promoting sexual health? .Journal of Sex Research, 45(3), 277-286. doi:10.1080/00224490802204480

[38]. Schreck, L. L. (1999). Safer-sex programs increase condom use among black adolescents. Family Planning Perspectives, 31(1), 4849

[39]. Seal, A. A., Minichiello, V., \& Omodei, M. M. (1997). Young women's sexual risk taking behaviour: Re-visiting the influences of sexual self-efficacy and sexual self-esteem. International Journal of STD \& AIDS, 8(3), 159-165. doi:10.1258/0956462971919822

[40]. Siedman, S.N, \& Rieder, R.O. (1994). A review of sexual behaviour in the United States. The American Journal of Psychiatry, 15(3), 330-341. 1994-29484-001

[41]. Taffa, Negussie; Bjune, Gunnar; Sundby, Johanne; Gaustad, Peter; Alestrøm, Anette (2002). Prevalence of gonococcal and Chlamydia infections among youth in Addis Abbaba, Ethiopia. Sexually Transmitted Diseases. 29 (12), p828. 6p. 3

[42]. Tsai, C., Chuang, S., Liang, J., \& Tsai, M. (2011). Self-efficacy in Internet-based learning environments: A literature review. Journal of Educational Technology \& Society, 14(4), 222-240

[43]. Wild, L.G, Bhana, A. \&Lombard, C. (2004). Substance abuse, suicidality and self-esteem in South African Adolescents. Journal of Drug Education, 34(1), 1-17 